\title{
The Misdiagnosis of CIDP: A Review
}

Jeffrey A. Allen

Received: February 11, 2020 / Published online: March 26, 2020

(c) The Author(s) 2020

\section{ABSTRACT}

There is a growing realization that many patients are incorrectly diagnosed with chronic inflammatory demyelinating polyneuropathy (CIDP), with at least half of patients that carry a diagnosis of CIDP in the USA possibly having a different explanation for their neuropathy or having no neuropathy at all. Many misdiagnosed patients go on to receive costly and potentially harmful treatments for a disease that they do not have, while at the same time missing an opportunity to treat their true ailment. The cost of misdiagnosis on patients and society is not trivial. Many factors contribute to misdiagnosis. Particular points of vulnerability include the evaluation of "atypical" CIDP, interpretation of equivocal nerve conduction studies, over-reliance on elevations in cerebrospinal fluid protein concentration in indeterminate ranges, and placing excessive diagnostic weight on subjective changes following the initiation of immunotherapy. In addition to heighted awareness of the challenges, adherence to CIDP diagnostic guidelines, utilization of objective metrics to

Digital Features To view digital features for this article go to: https://doi.org/10.6084/m9.figshare.11956485.

\section{J. A. Allen ( $\square)$}

Department of Neurology, University of Minnesota, Minneapolis, USA

e-mail: jaallen@umn.edu document clinical change, and referrals to CIDP centers of excellence are strategies that may improve diagnostic accuracy.

Keywords: Chronic inflammatory demyelinating polyneuropathy; CIDP; Neuropathy

\section{Key Summary Points}

Chronic inflammatory demyelinating polyneuropathy (CIDP) is frequently misdiagnosed.

Of the clinical phenotypes, "atypical" CIDP is most vulnerable to misdiagnosis.

On nerve conduction studies, particular attention to amplitude-dependant slowing, slowing restricted to compressible sites, and mild/moderate slowing in diabetic patients may minimize electrophysiologic interpretive errors.

Adoption of higher age-dependent cerebrospinal fluid (CSF) reference values may improve CSF diagnostic specificity.

Objective metrics of clinical change are strongly encouraged when clinical change is used to support the diagnosis of CIDP or justify ongoing immunotherapy. 


\section{INTRODUCTION}

Chronic inflammatory demyelinating polyneuropathy (CIDP) is an immune-mediated peripheral nerve disorder characterized by progressive or relapsing motor or sensory symptoms [1]. It is a rare disorder that affects 1.0-8.9 persons per 100,000 population [2] and has an incidence of up to 1.6 per 100,000 persons per year [3]. Stated another way, in a relatively large community of one million inhabitants, there may be as few as only ten and not more than 90 affected individuals. In less densely populated areas, as is the case across many regions of the USA, the occurrence of CIDP should become scarce, in proportion to the population density of the community.

Although there is a premium on early diagnosis and treatment, such that irreversible disability can be avoided, it is now well understood that CIDP is frequently misdiagnosed. The misdiagnosis problem was first publicly raised by several CIDP experts in an editorial published in 2013 [4]. In that editorial, Cornblath et al. highlighted the disturbing observation that patients misdiagnosed with CIDP were frequently encountered in their clinics, prompting the authors to call for renewed vigor for adopting a rigorous approach to the diagnosis and treatment of CIDP [4]. In addition to direct clinical observation, these authors also noted that in the USA there were regional "pockets" of CIDP in which relatively small communities had large numbers of CIDP patients, a finding that is just not possible based upon what is currently known on CIDP epidemiology [4]. These observations have fueled the misdiagnosis issue and prompted efforts to quantify the extent of the problem.

In 2015, a review of patients treated at a tertiary care center uncovered that almost half $(47 \%)$ of patients who were diagnosed and often treated as having CIDP did not actually have that condition [5]. The alternative diagnoses were heterogeneous, and in some cases no neuropathy was present at all. Two subsequent studies independently explored the misdiagnosis question in different populations of patients. In both studies the investigators collaborated with different home infusion specialty pharmacies in order to review patient records and draw diagnostic conclusions. The findings were highly complementary. Only 11\% [6] and 19\% [7] of patients diagnosed and treated as having CIDP in these community-based settings met minimum CIDP diagnostic standards [6, 7]. Although in many cases a diagnostic opinion could not be reached due to poor or incomplete documentation, the findings were nonetheless alarming.

Within the USA, the diagnosis problem is ubiquitous. While some regions appear to struggle more than others, based upon published data, misdiagnosis is not limited to a particular geographic region or to only community providers. Misdiagnosis is also unlikely to be limited to the USA. While many clinicians across Europe and Asia would be surprised to learn that the frequency of misdiagnosis is as high in their areas as that found in the USA, most agree that the problems are unlikely to be confined to a single country (personal communications).

Now that it has been clearly shown that misdiagnosis is frequent, the next question is why. What mistakes are commonly made? As there is no reliable biomarker by which to diagnose CIDP, to arrive at a diagnostic conclusion the clinician is required to collect detailed health history and physical assessment data, perform electrophysiologic studies and interpret the results, and sometimes use other data. Utilization of one of the more than 15 sets of CIDP diagnostic criteria can be a valuable tool to organize and proportionally integrate the findings [8-11]. While some of the diagnostic criteria sets were developed for research purposes, modern diagnostic criteria, such as those proposed by the European Federation of Neurological Societies/Peripheral Nerve Society (EFNS/PNS) [8], were developed for use during daily clinical care in addition to clinical trials. Although the guidelines are widely available and free to use in the public domain, rarely are they adopted during routine practice [6-8]. In particular, when no specific guideline is referenced, there are a number of obstacles that can be challenging to navigate. The aim of this review is to highlight some of the specific 
pitfalls that are encountered by the clinician during the diagnostic process.

This article is based on previously conducted studies and does not contain any studies with human participants or animals performed by the author.

\section{CLINICAL PITFALLS}

Chronic inflammatory demyelinating polyneuropathy is now recognized as a syndrome with both "typical" and "atypical" variants (Table 1) [8]. A designation of "typical" CIDP has been adopted by the EFNS/PNS to describe patients with CIDP who have relatively symmetric proximal and distal weakness and sensory dysfunction in all extremities. Similar to "typical" CIDP, "atypical" CIDP has at its core the disruption of motor and/or sensory peripheral nerve function, but it differs from "typical" CIDP either by the pattern of involvement or the modality predominantly affected. Recognized "atypical" variants that are still considered CIDP include distal CIDP (sometimes referred to as distal acquired demyelinating symmetric [DADS] neuropathy [12]), multifocal CIDP (also called Lewis-Sumner syndrome [13] or multifocal acquired demyelinating sensory and motor [MADSAM] neuropathy), sensory CIDP [14], and motor CIDP [15]. Regardless of the variant, the neuropathy must evolve over 2 months or more in a stepwise or progressive pattern.

Although the motor and sensory symptoms are the defining clinical features of CIDP, other symptoms have been clearly recognized in those patients with well-documented CIDP. Fatigue is a common complaint and may be present in up to $75 \%$ of patients [16]. Pain, typically in the distal extremities, may affect one-third or more patients [17]. Tremor (50\% of patients) [18], mild autonomic dysfunction (25\%) [19], and cranial nerve dysfunction (5-20\%) [20] usually involving the facial nerve infrequently develop. Only very rarely does respiratory failure occur. From a management perspective, these symptoms ought not to be dismissed, but from a diagnostic perspective an over-interpretation of any one of these features
Table 1 Typical chronic inflammatory demyelinating polyneuropathy and atypical variants

\begin{tabular}{|c|c|c|}
\hline Variant & Symptoms & Signs \\
\hline \multicolumn{3}{|l|}{ Typical CIDP } \\
\hline CIDP & $\begin{array}{l}\text { Proximal and distal } \\
\text { weakness and } \\
\text { numbness }\end{array}$ & $\begin{array}{l}\text { Absent or } \downarrow \\
\text { DTR in all } \\
\text { limbs }\end{array}$ \\
\hline \multicolumn{3}{|l|}{ Atypical CIDP } \\
\hline $\begin{array}{l}\text { Distal CIDP or } \\
\text { DADS }\end{array}$ & $\begin{array}{l}\text { Predominantly } \\
\text { distal, } \\
\text { sensory more than } \\
\text { motor, may have } \\
\text { ataxia }\end{array}$ & $\begin{array}{l}\text { DTR may be } \\
\text { normal or } \downarrow \\
\text { in proximal } \\
\text { areas }\end{array}$ \\
\hline $\begin{array}{l}\text { Multifocal } \\
\text { CIDP or } \\
\text { Lewis-Sumner } \\
\text { syndrome or } \\
\text { MADSAM }\end{array}$ & $\begin{array}{l}\text { Asymmetric motor } \\
\text { and sensory }\end{array}$ & $\begin{array}{l}\text { DTR may be } \\
\text { normal in } \\
\text { unaffected } \\
\text { limb }\end{array}$ \\
\hline Motor CIDP & $\begin{array}{l}\text { Proximal and distal, } \\
\text { symmetric, motor }\end{array}$ & $\begin{array}{c}\text { DTR generally } \\
\quad \downarrow\end{array}$ \\
\hline Sensory CIDP & $\begin{array}{l}\text { Proximal and distal, } \\
\text { symmetric, } \\
\text { sensory, may have } \\
\text { ataxia }\end{array}$ & $\begin{array}{l}\text { Absent or } \downarrow \\
\text { DTR in all } \\
\text { limbs }\end{array}$ \\
\hline
\end{tabular}

CIDP Chronic inflammatory demyelinating polyneuropathy, $D A D S$ distal acquired demyelinating symmetric (neuropathy), DTR deep tendon reflex, MADSAM multifocal acquired demyelinating sensory and motor (neuropathy), $\downarrow$ decreased

is the grounds for misdiagnosis. Fatigue should not be interpreted as weakness or power failure, and pain should not be interpreted as sensory loss. Clinically meaningful autonomic dysfunction is distinctly unusual in CIDP. As a general rule, if the defining symptom of the disease is pain, fatigue, or a similar nebulous symptom absent the hallmarks of numbness and/or weakness in a pattern and distribution that conforms to one of the defined variants, then the diagnosis of CIDP is unlikely to be correct. 
Particular attention needs to be placed on patients with "atypical" CIDP. Relatively speaking, "typical" CIDP is a more straightforward diagnosis when patients manifest a neuropathy that evolves over $\geq 2$ months and is characterized by symmetric proximal weakness in all four limbs. Although even in this setting electrophysiologic studies are important to provide evidence of peripheral nerve demyelination, a diagnosis of "typical" CIDP can confidently be made provided no serum paraprotein is present and no genetic abnormalities are suspected [9]. Conversely, "atypical" CIDP is a more challenging diagnosis. Distal CIDP is easy to confuse with more common length-dependent axonal neuropathies or genetically determined neuropathies. Multifocal CIDP may be confused with a mononeuropathy multiplex from inflammatory, genetically determined, or traumatic causes. Motor CIDP mimics include multifocal motor neuropathy and motor neuron disorder, while sensory CIDP can be confused with a host of neuropathic and non-neuropathic conditions that have a disturbance of skin sensation. While existing diagnostic criteria can be helpful to differentiate "atypical" CIDP from the mimics, in their present form the definitions used to define the "atypical" variants are sub-optimal [8]. In one series of misdiagnosed patients, 44\% of patients misdiagnosed as CIDP were found to satisfy EFNS/PNS clinical criteria, but in each case the classification was "atypical" [5]. Even if a more detailed definition is issued, still the nuanced nature of the "atypical" variants leaves them vulnerable to misinterpretation.

The rarity of "atypical" CIDP also presents challenges. Although between 31 and $48 \%$ of patients may have an "atypical" phenotype early in the disease course, substantial numbers evolve to a "typical" phenotype such that over time "atypical" patterns may represent only $18 \%$ of the full pool of CIDP patients [21, 22]. The individual "atypical" variants hence become even scarcer and harder to identify. Distal CIDP (DADS) is estimated to represent only $7-15 \%$ of all patients with CIDP. Sensory CIDP may occur in $3.5-14 \%$ of patients, while the motor variant has been reported in $4-9 \%$ of all patients with CIDP. Similar estimates have been described for asymmetric CIDP, ranging between 4 and 14\% of the entire pool of CIDP patients $[21,22]$. Considering the rarity of CIDP to begin with, it is not a practical expectation for clinicians without substantial familiarity with CIDP to be able to recognize the rare variants of this rare disease with any high degree of certainty. When a diagnosis of "atypical" CIDP is suspected, it is important to obtain ancillary data that supports the diagnosis and to thoroughly investigate for diagnostic mimics. In situations in which there is diagnostic ambiguity, and especially for patients thought to have one of the atypical CIDP variants, obtaining a second opinion from a GuillainBarré Syndrome (GBS)-CIDP center of excellence is to be encouraged (https://www.gbscidp.org).

While most patients with CIDP have no specific biologic diagnostic marker, it is now known that antibodies to the nodal and paranodal antigens neurofascin 155 (NF155), neurofascin 140/186 (NF140), and contactin-1 (CNTN1) can be detected in 10-15\% of patients with CIDP [23-25]. These antibodies are poised not only to improve the diagnostic landscape of CIDP, but may provide insight into best treatment practices among those who harbor the antibodies. Individuals with anti-NF155 antibodies typically are younger at disease onset and have disabling tremor, sensory ataxia, predominant distal weakness, and very high cerebrospinal fluid (CSF) protein levels $[23,24]$. The phenotype associated with CNTN1 antibodies is more variable, with some patients presenting at advanced ages with rapid and aggressive symptom onset, predominant motor involvement, early evidence of denervation on electromyography testing, ataxia, and poor response to intravenous immunoglobulin (IVIg), and others presenting with clinical features similar to the phenotype associated with anti-NF155 antibodies [25]. From a diagnostic perspective, recognition of these clinical features may prompt antibody exploration if testing is available, as a positive result may have important treatment implications. Both anti-NF155 and anti-CNTN1 antibodies are of the IgG4 isotype. IgG4 autoantibodies are produced by regulatory $B$ cells and cannot efficiently fix complement or 
bind to immunoglobulin receptors [23-25]. This may be one reason why patients with antiNF155 and anti-CNT1 antibodies respond poorly to IVIg but often improve with corticosteroid treatment. B-cell depletion therapy with rituximab has been associated with meaningful beneficial responses in other IgG4mediated diseases and may also be an effective option in patients with anti-CNTN1 and NF155 antibodies who do not respond to or do not tolerate corticosteroids.

\section{ELECTROPHYSIOLOGICAL PITFALLS}

Accurately diagnosing CIDP relies heavily on the documentation of peripheral nerve demyelination as evidenced by nerve conduction studies (NCS). Characteristic electrophysiologic abnormalities that typically indicate demyelination include prolongation of distal latency, slowing of conduction velocity, prolongation of duration of distal compound muscle action potential, conduction block, temporal dispersion, and minimum prolongation of F-wave latency. One challenging aspect of interpeting the results of NCS is understanding how many nerves need to be abnormal and to what degree any individual nerve needs to be abnormal in order to confidently conclude that demyelination is present. While many electrodiagnostic criteria are available by which to guide this process, those proposed by the EFNS/PNS appear to have the most favorable blend of sensitivity and specificity and, therefore, are most applicable for use during clinical trials and routine daily care [8]. EFNS/PNS criteria grade electrophysiologic abnormalities as "definite," "possible," or "probable" based upon the number and severity of the affected nerves. Minimum ("possible") electrodiagnostic criteria can be satisfied when only a single pre-defined demyelinating abnormality is present. When NCS are performed on five to eight motor nerves, the sensitivity of the EFNS/PNS electrodiagnostic criteria for a "possible" diagnosis approaches $100 \%$ (sensitivity $99.2 \%$, specificity 61\%) [26]. Even so, NCS are not a perfect representation of CIDP. If the abnormalities are restricted to sensory nerves, as in the case of sensory CIDP variants, no diagnostic changes may be appreciated. Likewise, if only very proximal segments are affected, for example, at the plexus or root level, they may not be captured in routine NCS [27]. Questions also remain on how intermediate degrees of amplitude-independent slowing of conduction velocity should be interpreted. Despite these limitations, with few exceptions NCS remain one of the diagnostic pillars of CIDP.

There are several pitfalls that have been recognized during the electrophysiologic examination that may lead to an erroneous diagnosis of CIDP. The most common mistake is when electrodiagnostic data are interpreted as "demyelinating" but are better explained by a different pathophysiology [28]. Such interpretive errors can occur in the context of amplitudedependent slowing, when slowing is restricted to compressible sites, and amplitude-independent slowing in diabetic patients. The slowing of amplitude-dependent conduction velocity is a well-described consequence of the loss of fast conducting fibers $[29,30]$ and can be appreciated in the context of axonal neuropathies and motor neuron disease. Compressible sites and entrapment zones are not preferentially affected in CIDP and should not be considered supportive of a generalized demyelinating polyneuropathy absent any demyelinating change in contiguous segments [31]. While the slowing of conduction velocity in diabetic patients presents some unique challenges, the presence of conduction block and temporal dispersion are distinctly unusual in diabetic neuropathy [32]. More importantly, the severity of slowing in both amplitude-independent diabetic neuropathies and amplitude-dependent axonal neuropathies should not exceed $30 \%$ of the lower limit of normal, as defined by EFNS/ PNS criteria [8]. Especially within these contexts, mild to moderate degrees of slowing (i.e., reduction of motor conduction velocity to $<30 \%$ below the lower limit of normal) should not be considered indicative of a generalized demyelinating polyneuropathy.

Temperature can also affect the interpretation of the electrodiagnostic study. Failure to warm a lower limb to $30^{\circ} \mathrm{C}$ or an upper limb to $33^{\circ} \mathrm{C}$ may result in erroneous prolongation of 
distal latency or slowing of conduction velocity. All data and waveforms should be carefully inspected for quality and accuracy. Particular attention needs be paid to the placement of latency markers, as small errors in placement may cause large changes in velocity over short nerve segments. Vulnerability to marker placement errors is especially high when motor response amplitudes are small or when electrical interference skews the accurate identification of action potential onset. The results of electrophysiologic studies that use the fibular nerve to the EDB (extensor digitorum brevis) muscle as the key component of the diagnosis of a demyelinating neuropathy should be interpreted with caution, especially when the motor response amplitude is $<1 \mathrm{mV}$. When fibular to EDB amplitude-dependent slowing is present, NCS to proximal muscles may be helpful. Finally, all electrophysiologic findings require clinical correlation. Even unequivocal demyelination on NCS is not diagnostic of CIDP absent the hallmark clinical features. When demyelination is present but the clinical features are irregular for CIDP, an alternative explanation for the demyelinating polyneuropathy should be pursued (Table 2 ).

\section{LABORATORY PITFALLS}

Especially in the absence of a CIDP diagnostic biomarker, the simple laboratory value of the CSF total protein test can provide helpful information supportive of the diagnosis of CIDP. The CSF total protein test classically reveals cytoalbuminologic dissociation in 80-95\% of those with typical CIDP. However, interpretation of precisely what constitutes CSF protein elevation is not as straightforward as it may appear. There is no universal CSF protein upper reference limit for any disease state. While more than $85 \%$ of laboratories worldwide consider $0.45 \mathrm{~g} / \mathrm{L}$ to be the upper CSF reference limit, lower or higher reference limits are occasionally utilized [33]. Several studies have shown that the widely used cutoff of $0.45 \mathrm{~g} / \mathrm{L}$ is erroneously low $[34,35]$. Implementation of CSF values of $0.50 \mathrm{~g} / \mathrm{L}$ for patients aged $\leq 50$ years and $0.60 \mathrm{~g} / \mathrm{L}$ for those aged $>50$ years have been proposed as a better standard CSF reference value [36]. Adoption of these higher age-dependent reference values in a population of CIDP patients was shown to improve CIDP diagnostic specificity, without a meaningful compromise in diagnostic sensitivity [37]. These findings suggest that CSF protein levels of between 0.45 and $0.6 \mathrm{~g} / \mathrm{L}$ should not be considered supportive of the diagnosis of CIDP, especially in individuals aged $>50$ years. Even when CSF protein levels exceed $0.6 \mathrm{~g} / \mathrm{L}$, interpretive scrutiny is needed. No degree of cytoalbuminologic dissociation is pathognomonic for CIDP. CSF protein is a crude estimate of abnormal permeability that may be influenced by age and comorbid medical conditions, including degenerative spinal stenosis and diabetes mellitus, among others. Diagnostic reconsideration is encouraged for patients diagnosed with CIDP based upon a CSF protein level $>0.6 \mathrm{~g} / \mathrm{L}$ who do not harbor the characteristic clinical and electrophysiologic features of CIDP. While these conclusions may question the role of CSF during the CIDP diagnostic process, CSF can also serve to help identify mimics of CIDP. When the white blood cell count in the CSF exceeds 10 per $\mathrm{mm}^{3}$ and especially increases above 50 per $\mathrm{mm}^{3}$, attention may turn to infectious or infiltrative disorders, including human immunodeficiency virus, Lyme disease, sarcoidosis, and lymphoma [38].

\section{PITFALLS WHEN INTERPRETING THE TREATMENT RESPONSE}

Similar to many conditions that are without a diagnostic biomarker, improvement after treatment with immunotherapy is considered supportive of the diagnosis of CIDP [8]. Such "tests of treatment" can be diagnostically helpful when the differential diagnosis is narrow, pretest probability is high, and there is a measurable objective outcome [39]. Problems occur when the measures used to define a positive "test of treatment" are loosely defined. Subjective responses may be complicated by a number of factors, including placebo response, desire of the patient and physician to change the course 
Table 2 Demyelinating polyneuropathy differential diagnosis

\begin{tabular}{|c|c|c|c|}
\hline Disease & Comment & Electrophysiology & $\begin{array}{l}\text { CSF } \\
\text { protein }\end{array}$ \\
\hline \multicolumn{4}{|l|}{ Immune } \\
\hline AIDP & Progressive over $<4$ weeks & $\begin{array}{l}\text { F waves prolonged early; demyelinating } \\
\text { features peak 2-3 weeks }\end{array}$ & $\begin{array}{c}\text { Normal } \\
\text { or } \uparrow\end{array}$ \\
\hline MAG & $\begin{array}{l}\text { Distally accentuated, with slow progression } \\
\text { most common }\end{array}$ & Distally accentuated slowing & $\uparrow$ \\
\hline MMN & Multifocal; spared sensation & $\mathrm{CB}$ in many & $\begin{array}{c}\text { Normal } \\
\text { or } \uparrow\end{array}$ \\
\hline $\begin{array}{l}\text { POEMS (see } \\
\text { Comment column) }\end{array}$ & $\begin{array}{l}\text { Polyneuropathy; Organomegaly; } \\
\text { Endocrinopathy; M-protein; Skin } \\
\text { changes }\end{array}$ & $\begin{array}{l}\uparrow \text { axonal injury and more uniform CV } \\
\text { slowing than usually seen in CIDP }\end{array}$ & $\uparrow$ \\
\hline Drug-induced & $\begin{array}{l}\text { Tumor necrosis factor-alpha antagonists } \\
\text { (infliximab, adalimumab, etanercept); } \\
\text { interferon-alpha therapy, tacrolimus, } \\
\text { bortezomib, pembrolizumab }\end{array}$ & May be indistinguishable from CIDP & $\begin{array}{c}\text { Normal } \\
\text { or } \uparrow\end{array}$ \\
\hline \multicolumn{4}{|l|}{ Metabolic } \\
\hline Diabetic & $\begin{array}{l}\text { Usually length-dependent with small fiber } \\
\text { involvement; plexopathy may be abrupt } \\
\text { onset }\end{array}$ & $\begin{array}{l}\text { Usually axonal; may have mild/moderate } \\
\text { demyelination without } \mathrm{TD} \text { or } \mathrm{CB}\end{array}$ & $\begin{array}{c}\text { Normal } \\
\text { or } \uparrow\end{array}$ \\
\hline Uremic & $\begin{array}{l}\text { Glomerular filtration rate } \\
\text { typically }<12 \mathrm{~mL} / \mathrm{min}\end{array}$ & $\begin{array}{l}\text { Usually axonal; may have mild/moderate } \\
\text { demyelination }\end{array}$ & $\begin{array}{c}\text { Normal } \\
\text { or } \uparrow\end{array}$ \\
\hline \multicolumn{4}{|l|}{ Toxic } \\
\hline Amiodarone & $\begin{array}{l}\text { Subacute/chronic; symmetric sensorimotor; } \\
\text { may affect proximal muscles; } \uparrow \text { risk if } \\
\text { exposure }>1 \text { year }\end{array}$ & $\begin{array}{l}\text { Axon loss }+ \text { mild to moderate } \mathrm{CV} \\
\text { slowing and prolonged } \mathrm{DL}\end{array}$ & Normal \\
\hline Ethylene glycol & $\begin{array}{l}\text { CNS; CN changes; renal and cardiac } \\
\text { toxicity }\end{array}$ & Axon loss predominates & $\uparrow$ \\
\hline Diptheria & $\begin{array}{l}\text { Usually evolves over 2-3 weeks; } \pm \text { CSF } \\
\text { pleocytosis,; bulbar and respiratory } \\
\text { weakness common }\end{array}$ & May be indistinguishable from CIDP & $\uparrow$ \\
\hline n-Hexane & $\begin{array}{l}\text { May mimic distal CIDP, with } \\
\text { distal }>\text { proximal sensory and motor } \\
\text { symptoms evolving over months }\end{array}$ & $\begin{array}{l}\text { Usually axonal; may have mild/moderate } \\
\text { demyelination or } \mathrm{CB}\end{array}$ & Normal \\
\hline \multicolumn{4}{|l|}{ Systemic } \\
\hline $\begin{array}{l}\text { Amyloid, acquired or } \\
\text { hTTR }\end{array}$ & $\begin{array}{l}\text { Prominent pain and autonomic } \\
\text { dysfunction; cardiac or gastrointestinal } \\
\text { manifestations }\end{array}$ & $\begin{array}{l}\text { Typically axonal; mild to moderate CV } \\
\text { slowing may be seen }\end{array}$ & $\begin{array}{l}\text { Normal } \\
\text { or } \uparrow\end{array}$ \\
\hline
\end{tabular}


Table 2 continued

\begin{tabular}{|c|c|c|c|}
\hline Disease & Comment & Electrophysiology & $\begin{array}{l}\text { CSF } \\
\text { protein }\end{array}$ \\
\hline Sarcoid & $\begin{array}{l}\text { Pulmonary, skin, ocular, muscle, endocrine, } \\
\mathrm{CN} \text {, or CNS involvement }\end{array}$ & $\begin{array}{l}\text { Typically multifocal axonal or LDPN; } \\
\text { rarely demyelinating with CB }\end{array}$ & $\begin{array}{c}\text { Normal } \\
\text { or } \uparrow\end{array}$ \\
\hline \multicolumn{4}{|l|}{ Malignancy } \\
\hline Neurolymphomatosis & $\begin{array}{l}\text { Often multiple mononeuropathy pattern; } \\
\text { pain common; CNs may be affected; may } \\
\text { improve with immunotherapy }\end{array}$ & $\begin{array}{l}\text { Usually axonal, but may have multifocal } \\
\text { demyelinating features similar to CIDP }\end{array}$ & $\begin{array}{c}\text { Normal } \\
\text { or } \uparrow\end{array}$ \\
\hline Paraneoplastic & $\begin{array}{l}\text { Asymmetric sensory or sensorimotor often } \\
\text { preferentially affecting DRG; } \\
\text { concomitant CNS disorder may occur }\end{array}$ & $\begin{array}{l}\text { Sensory responses often diffusely } \\
\text { attenuated or absent; motor responses } \\
\text { usually normal or show axonal changes, } \\
\text { but demyelination mimicking CIDP } \\
\text { has been reported }\end{array}$ & $\uparrow$ \\
\hline \multicolumn{4}{|l|}{ Inherited } \\
\hline HNPP & $\begin{array}{l}\text { Symptoms triggered by mild trauma or } \\
\text { compression }\end{array}$ & $\mathrm{CB}$ accentuated at compressible sites & $\begin{array}{c}\text { Normal } \\
\text { or } \uparrow\end{array}$ \\
\hline CMT 1 & $\begin{array}{l}\text { Slow progression, often with onset at early } \\
\text { age }\end{array}$ & $\begin{array}{l}\text { Uniform CV slowing; typically without } \\
\text { CB or TD (exceptions may occur) }\end{array}$ & $\begin{array}{l}\text { Normal } \\
\text { or } \uparrow\end{array}$ \\
\hline Farber's & $\begin{array}{l}\text { X-linked; onset childhood or adolescence; } \\
\text { pain; angiokeratomas; premature } \\
\text { atherosclerosis }\end{array}$ & $\begin{array}{l}\text { Slow CV and } \uparrow \mathrm{DL} \text {; may be normal early } \\
\text { in disease }\end{array}$ & $\begin{array}{l}\text { Normal } \\
\text { or } \uparrow\end{array}$ \\
\hline Refsum & $\begin{array}{l}\text { AR; onset usually in infancy or early adult; } \\
\text { course may be progressive or relapsing; } \\
\text { retinitis pigmentosa, cerebellar ataxia, } \\
\text { hearing loss, cardiac conduction disease }\end{array}$ & Demyelinating with severe CV slowing & $\uparrow$ \\
\hline MLD & $\begin{array}{l}\text { AR; arylsulfatase A mutation; onset most } \\
\text { common in late infancy, followed } \\
\text { by adolescence and then as adult; } \\
\text { multiple CNS deficits }\end{array}$ & $\mathrm{CV}$ slowing without $\mathrm{CB}$ & $\uparrow$ \\
\hline Krabbe & $\begin{array}{l}\text { AR; galactosylceramide } \beta \text {-galactosidase } \\
\text { mutation; onset in infancy, adolescence, } \\
\text { adulthood; multiple CNS deficits }\end{array}$ & Slow $\mathrm{CV}$, occasional with $\mathrm{CB}$ & $\uparrow$ \\
\hline
\end{tabular}


Table 2 continued

\begin{tabular}{llll}
\hline Disease & Comment & Electrophysiology & $\begin{array}{l}\text { CSF } \\
\text { protein }\end{array}$ \\
& & \\
\hline
\end{tabular}

Mitochondiral

MNGIE Onset childhood or adolescence; myopathy; Demyelinating with CV slowing; CB and $\uparrow$ external ophthalmoplegia; neuropathy; TD in some patients gastrointestinal; encephalopathy (may be subclinical)

$A I D P$ Acute inflammatory demyelinating polyradiculoneuropathy, $A R$ autosomal recessive, $C B$ conduction block, $C N$ cranial nerve, $C N S$ central nervous system, $C V$ conduction velocity, $D R G$ dorsal root ganglion, $C S F$ cerebrospinal fluid, $D R G$ dorsal root ganglia, $D L$ distal latency, HNPP hereditary neuropathy with pressure palsies, $b T T R$ hereditary transthyretin amyloidosis, $L D P N$ length-dependent polyneuropathy, MAG Anti-myelin-associated glycoprotein, $M L D$ metachromatic leukodystrophy, $M M N$ multifocal motor neuropathy $T D$ temporal dispersion, $\uparrow$ increased

of the illness, and non-specific treatment effects unrelated to disease response. Even objective responses are not disease specific. In a series of patients misdiagnosed with CIDP but who were nonetheless treated as though they had CIDP, $85 \%$ felt better with immunotherapy when the benefit was broadly and subjectively defined [5]. Only 19\% of misdiagnosed patients demonstrated objective evidence of improvement, and in most cases those patients were found to have immune-mediated disorders that were mismanaged as CIDP. One frequently observed pitfall with subjective interpretation of the treatment response is the amount of emphasis placed upon symptoms like fatigue and pain. Hyper-vigilance of improvement of only these non-specific symptoms absent improvement in the clinical hallmarks of CIDP may lead the interpretation of the treatment response-and subsequently the entire diagnostic processastray.

There are practical solutions that can be employed to improve objective assessment of treatment benefit. While there is a perception that outcome measures are "for research only," many outcome measures used in CIDP clinical trials are well suited for adoption during routine clinical care [40]. Ideal outcome metrics during routine care should be rapidly and easily obtained, with the results being quantifiable, consistent, and immediately interpretable. Assessing strength impairment by grip strength testing or the Medical Research Council scale for measuring muscle strength, disability assessment by the I-RODS (Inflammatory Raschbuilt Overall Disability Scale) or INCAT (Inflammatory Neuropathy Cause and Treatment) disability scores, and quality of life impairment by the PGIC (Patient Global Impression of Change) or CAP-PRI (Chronic Acquired Polyneuropathy- Patient Reported Index) scores fulfill requirements for daily use in the clinic setting [40]. The routine collection of such outcomes can provide the clinician with invaluable data to better assess benefit following treatment or to define relapse or remission. While implementation of these tools may appear daunting, all data can be collected quickly and with minimal training by physicians, office staff, or by the patients themselves. With repeated use these tools add efficiency and quality to the clinic visit with an insignificant degree of added burden.

\section{CONCLUSIONS}

The problem of misdiagnosing CIDP in the USA, and probably in other parts of the world, is very real-and with that problem come substantial physical, emotional, and financial burdens on both individual patients and society. The task of correctly diagnosing CIDP is often not easy, and the consequences of getting the diagnosis wrong are not trivial. From a safety perspective, the risks assumed from immunotherapy 
exposure are obvious. The therapies we use to treat CIDP are not benign, nor are they (in most cases) cheap. In 2011, the mean health care plan paid out annually US $\$ 108,016$ per CIDP patient treated with IVIg, with pharmacy expenses accounting for the majority of costs [41]. As the armamentarium of immunotherapies grows, costs and risk will most certainly grow as well. There is an unquestionable need to diagnosis CIDP early and to initiate treatment prior to the onset of potentially irreversible neurologic deficits. Equally important is improving the accuracy of the diagnosis such that the risks and costs assumed with any CIDP treatment are balanced with the likelihood that the treatment will be beneficial.

There are several opportunities to improve CIDP diagnostic accuracy. Of particular importance is: (1) heightened attention to "atypical" variants of CIDP; (2) astute clinical correlation when electrophysiologic findings show only amplitude-dependent slowing, are mild or moderate in diabetic patients, are restricted to compressible sites, do not satisfy demyelinating criteria, or are confined to the lower limbs; (3) cautious interpretation of CSF protein values between 0.45 and $0.6 \mathrm{~g} / \mathrm{L}$; and (4) adoption of objective metrics of "improvement" if "improvement after immunotherapy" is used to support the diagnosis. Utilization of CIDP diagnostic guidelines during routine clinical practice can be instrumental to improving diagnostic accuracy [8]. Modern guidelines are freely available and easily accessible in the public domain. Finally, given the rarity of the disease, obtaining a second opinion from a CIDP center of excellence (https:// www.gbs-cidp.org/support/centers-of-excellence/) may be valuable. Patients with "atypical" CIDP and those that do not respond to first-line CIDP therapies may especially benefit from a second look.

\section{ACKNOWLEDGEMENTS}

Funding. No funding or sponsorship was received for this study or publication of this article.
Authorship. The author meets the International Committee of Medical Journal Editors (ICMJE) criteria for authorship for this article, takes responsibility for the integrity of the work as a whole, and has given his approval for this version to be published.

Disclosures. Jeffrey A. Allen has provided consulting services to Akcea, Alexion, Argenyx, CSL Behring, Biotest, Kaba Infusions and Momenta.

Compliance with Ethics Guidelines. This article is based on previously conducted studies and does not contain any studies with human participants or animals performed by the author.

Data Availability. Data sharing is not applicable to this article as no datasets were generated or analyzed during the current study.

Open Access. This article is licensed under a Creative Commons Attribution-NonCommercial 4.0 International License, which permits any non-commercial use, sharing, adaptation, distribution and reproduction in any medium or format, as long as you give appropriate credit to the original author(s) and the source, provide a link to the Creative Commons licence, and indicate if changes were made. The images or other third party material in this article are included in the article's Creative Commons licence, unless indicated otherwise in a credit line to the material. If material is not included in the article's Creative Commons licence and your intended use is not permitted by statutory regulation or exceeds the permitted use, you will need to obtain permission directly from the copyright holder. To view a copy of this licence, visit http:// creativecommons.org/licenses/by-nc/4.0/.

\section{REFERENCES}

1. Allen JA. Chronic demyelinating polyneuropathies. Continuum (Minneap Minn). 2017;23(5, Peripheral Nerve and Motor Neuron Disorders):1310-31. 
2. Lunn MP, Manji H, Choudhary PP, et al. Chronic inflammatory demyelinating polyradiculoneuropathy: a prevalence study in south east England. J Neurol Neurosurg Psychiatry. 1999;66(5):677-80.

3. Laughlin RS, Dyck PJ, Melton LJ III, et al. Incidence and prevalence of CIDP and the association of diabetes mellitus. Neurology. 2009;73(1):39-45.

4. Cornblath DR, Gorson KC, Hughes RA, Merkies IS. Observations on chronic inflammatory demyelinating polyneuropathy: a plea for a rigorous approach to diagnosis and treatment. J Neurol Sci. 2013;330(1-2):2-3.

5. Allen JA, Lewis RA. CIDP diagnostic pitfalls and perception of treatment benefit. Neurology. 2015;85(6):498-504.

6. Allen JA, Gelinas DF, Lewis RA, et al. Optimizing the use of outcome measures in chronic inflammatory demyelinating polyneuropathy. US Neurol. 2017;13(1):26-34.

7. Levine TD, Katz JS, Barohn R, et al. Review process for IVIg treatment. Lessons learned from INSIGHTS neuropathy study. Neurol Clin Pract. 2018;8(5): 429-36.

8. Vanden Bergh PY, Hadden RD, Bouche P, et al. European Federation of Neurological Societies/Peripheral Nerve Society guideline on management of chronic inflammatory demyelinating polyradiculoneuropathy: report of a joint task force of the European Federation of Neurological Societies and the Peripheral NerveSociety-first revision. Eur J Neurol. 2010;17(3):356-63.

9. Koski CL, Baumgarten M, Magder LS, et al. Derivation and validation of diagnostic criteria for chronic inflammatory demyelinating polyneuropathy. J Neurol Sci. 2009;277(1-2):1-8.

10. Saperstein DS, Katz JS, Amato AA, Barohn RJ. Clinical spectrum of chronic acquired demyelinating polyneuropathies. Muscle Nerve. 2004;24(3): 311-24.

11. [No authors listed]. Research criteria for the diagnosis of chronic inflammatory demyelinating polyradiculoneuropathy (CIDP). Report from an Ad Hoc Subcommittee of the American Academy of Neurology AIDS Task Force. Neurology. 1991;41: 617-8.

12. Katz JS, Saperstein DS, Gronseth G, et al. Distal acquired demyelinating symmetric neuropathy. Neurology. 2000;54:615-20.

13. Lewis RA, Sumner AJ, Brown MJ, Asbury AK. Multifocal demyelinating neuropathy with persistent conduction block. Neurology. 1982;32:958-64.
14. Ayrignac X, Viala K, Koutlidis RM, et al. Sensory chronic inflammatory demyelinating polyneuropathy: an under-recognized entity? Muscle Nerve. 2013;48(5):727-32.

15. Sabatelli M, Madia F, Mignogna T, et al. Pure motor chronic inflammatory demyelinating polyneuropathy. J Neurol. 2001;248:772-7.

16. Boukhris S, Magy L, Gallouedec G, et al. Fatigue as the main presenting symptom of chronic inflammatory demyelinating polyradiculoneuropathy: a study of 11 cases. J Peripher Nerv Syst. 2005;10: 329-37.

17. Goebel A, Lecky B, Smith LJ, Lunn MP. Pain intensity and distribution in chronic inflammatory demyelinating polyneuropathy. Muscle Nerve. 2012;46(2):294-5.

18. Saifee TA, Schwingenschuh P, Reilly MM, et al. Tremor in inflammatory neuropathies. J Neurol Neurosurg Psychiatry. 2013;84(11):1282-7.

19. Figueroa JJ, Dyck PJ, Laughlin RS, et al. Autonomic dysfunction in chronic inflammatory demyelinating polyradiculoneuropathy. Neurology. 2012;78: 702-8.

20. Rotta FT, Sussman AT, Bradley WG, et al. The spectrum of chronic inflammatory demyelinating polyneuropathy. J Neurol Sci. 2000;173(2):129-39.

21. Doneddu PE, Cocito D, Manganelli F, et al. Atypical CIDP: diagnostic criteria, progression and treatment response. Data from the Italian CIDP Database. J Neurol Neurosurg Psychiatry. 2019;90(2): 125-32.

22. Ikeda S, Koike H, Nishi R, et al. Clinicopathological characteristics of subtypes of chronic inflammatory demyelinating polyradiculoneuropathy. J Neurol Neurosurg Psychiatry. 2019;90(9):988-96.

23. Querol L, Nogales-Gadea G, Rojas-Garcia R, et al. NF IgG4 antibodies in CIDP associate with disabling tremor and poor response to IVIg. Neurology. 2014;82(10):879-86.

24. Devaux JJ, Miura Y, Fukami Y, et al. Neurofascin155 IgG4 in chronic inflammatory demyelinating polyneuropathy. Neurology. 2016;86(9):800-7.

25. Querol L, Nogales-Gadea G, Rojas-Garcia R, et al. Antibodies to contactin-1 in chronic inflammatory demyelinating polyneuropathy. Ann Neurol. 2013;73(3):370-80.

26. Rajabally YA, Nicolas G, Piéret F, et al. Validity of diagnostic criteria for chronic inflammatory demyelinating polyneuropathy: a multicentre 
European study. J Neurol Neurosurg Psychiatry. 2009;80(12):1364-8.

27. Sinnreich M, Klein CJ, Daube JR, et al. Chronic immune sensory polyradiculopathy: a possibly treatable sensory ataxia. Neurology. 2004;63(9): 1662-9.

28. Allen JA, Ney J, Lewis RA. Electrodiagnostic errors contribute to chronic inflammatory demyelinating polyneuropathy misdiagnosis. Muscle Nerve. 2018;57(4):542-9.

29. Logigian EL, Kelly JJ, Adelman LS. Nerve conduction and biopsy correlation in over 100 consecutive patients with suspected polyneuropathy. Muscle Nerve. 1994;17:1010-20.

30. Feinberg DM, Preston DC, Shefner JM, Logigian EL. Amplitude-dependent slowing of conduction in amyotrophic lateral sclerosis and polyneuropathy. Muscle Nerve. 1999;22:937-40.

31. Rajabally YA, Narasimhan M. Electrophysiological entrapment syndromes in chronic inflammatory demyelinating polyneuropathy. Muscle Nerve. 2011;44:444-7.

32. Gorson KC, Ropper AH, Adelman LS, Weinberg DH. Influence of diabetes mellitus on chronic inflammatory demyelinating polyneuropathy. Muscle Nerve. 2000;23:37-433.

33. Bourque PR, Breiner A, Moher D, et al. Adult CSF total protein: higher upper reference limits should be considered worldwide. A web-based survey. J Neurol Sci. 2019;396:48-51.
34. Hegen $H$, Auer M, Zeileis A, Deisenhammer F. Upper reference limits for cerebrospinal fluid total protein and albumin quotient based on a large cohort of control patients: implications for increased clinical specificity. Clin Chem Lab Med. 2016;54(2):285-92.

35. McCudden CR, Brooks J, Figurado P, Bourque PR. Cerebrospinal fluid total protein reference intervals derived from 20 years of patient data. Clin Chem. 2017;63(12):1856-65.

36. Breiner A, Moher D, Brooks J, et al. Adult CSF total protein upper reference limits should be age-partitioned and significantly higher than $0.45 \mathrm{~g} / \mathrm{L}$ : a systematic review. J Neurol. 2019;266(3):616-24.

37. Breiner A, Bourque PR, Allen JA. Updated CSF total protein reference values improve CIDP diagnosis. Muscle Nerve. 2019;60:180-3.

38. Lucke IM, Peric S, van Lieverloo GGA, et al. Elevated leukocyte count in cerebrospinal fluid of patients with chronic inflammatory demyelinating polyneuropathy. J Peripher Nerv Syst. 2018;23(1): 49-544.

39. Glasziou P, Rose P, Heneghan C, Balla J. Diagnosis using "test of treatment". BMJ. 2009;338:b1312.

40. Allen JA, Merkies I, Lewis RA. Monitoring clinical course and treatment response in CIDP during routine care: a review of clinical and laboratory assessment measures. JAMA Neurol (in press).

41. Guptill JT, Bromberg MB, Zhu L, et al. Patient demographics and health plan paid costs in chronic inflammatory demyelinating polyneuropathy. Muscle Nerve. 2014;50(1):47-51. 